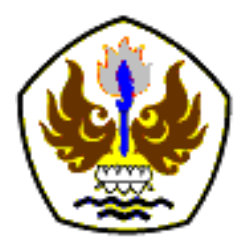

INFOMATEK

Volume 20 Nomor 1 Juni 2018

\title{
EVALUASI SIGNIFIKANSI METODE OPTIMASI DALAM MEMINIMUMKAN BIAYA PERENCANAAN PRODUKSI
}

\author{
Akhsani Nur Amalia*), Arum Sari \\ Program Studi Teknik Industri \\ Fakultas Teknik- Universitas Pasundan
}

\begin{abstract}
Abstrak:Tujuan dari penelitian ini adalah untuk mengetahui pengaruh metode optimasi untuk meminimumkan biaya perencanaan produksi. Analisis berbasis eksperimen dilakukan dengan menggunakan Graeco Latin Square Design. Faktor utamanya adalah metode perencanaan produksi dengan tiga level. Ketiga level ini yaitu metode optimasi, metode heuristik dengan strategi konstan dan metode heuristik dengan strategi sesuai demand. Sementara itu, faktor stabilitas demand, rasio biaya hiring dan lay off dan biaya simpan merupakan faktor nuisance. Hasil eksperimen membuktikan bahwa metode optimasi memiliki pengaruh yang signifikan dalam meminimumkan biaya perencanaan produksi. Uji level faktor menunjukkan bahwa metode optimasi paling baik digunakan untuk variasi demand tinggi, rasio biaya hiring dan lay off tinggi dan biaya simpan sedang. Hasil penelitian juga membuktikan bahwa pengaruh optimasi dapat menurunkan biaya perencanaan produksi sebesar $0,65 \%$ sampai dengan $17,8 \%$.
\end{abstract}

Kata kunci: Design of Experiment, Graeco Latin Square Design, Perencanaan Produksi

\section{PENDAHULUAN}

\subsection{Latar Belakang}

Sistem produksi merupakan sistem yang menonjol dalam masyarakat modern. Sistem ini membentuk dasar untuk membangun dan meningkatkan kekuatan ekonomi suatu negara. Tugas mengembangkan dan menjalankan sistem produksi telah semakin kompleks. Perubahan besar dalam produk, proses, manajemen teknologi, konsep dan budaya dalam memenuhi tantangan dan tuntutan. (Sipper, dkk., 1997, [1]). Perubahan

*akhsaninuramalia@gmail.com

Pertama diterima : 15 Januari 2018

Direvisi : 4 Mei 2018

Disetujui untuk publikasi: 4 Mei 2018 dalam sistem produksi ini akan berpengaruh terhadap teknik produksi.

Perencanaan produksi adalah aktivitas untuk menetapkan jumlah produk yang diproduksi, kapan produk tersebut harus selesai dan sumber-sumber yang dibutuhkan. Perencanaan produksi sebagai suatu perencanaan taktis yang bertujuan untuk memberikan keputusan yang optimum dengan biaya terkecil berdasarkan sumber daya yang dimiliki atau diperlukan dalam memenuhi permintaan. Terdapat beberapa metode yang dapat digunakan dalam perencanaan produksi. Salah satunya yaitu metode optimasi. Metode optimasi digunakan ketika 
solusi yang diharapkan bernilai optimal. Dalam metode optimasi dikenal salah satu model yang biasa digunakan untuk mendapatkan solusi yang optimal, yaitu Linear Programming. Linear Programming adalah perencanaan aktivitas - aktivitas untuk memperoleh suatu hasil yang optimum, yaitu suatu hasil yang mencapai tujuan terbaik di antara seluruh alternatif yang fisibel (Dimyati, dkk., 2010 [2]).

Perencanaan produksi dengan model Linear Programming akan memberikan solusi yang optimal. Tetapi, dalam prakteknya Linear Programming relatif sulit untuk diterapkan. Terutama untuk kasus yang kompleks. Sebenarnya terdapat metode lain yang lebih mudah untuk diterapkan, yaitu metode heuristik. Akan tetapi penggunaan metode heuristik belum tentu memberikan solusi yang optimal terhadap perencanaan produksi. Oleh karena itu, banyak penelitian yang telah dilakukan untuk menguji seberapa besar pengaruh metode optimasi dalam perencanaan produksi.

\subsection{Perumusan Penelitian}

Sejumlah penelitian menunjukkan bahwa ternyata penggunaan metode optimasi tidak memberikan perbedaan biaya perencanaan produksi yang signifikan. Misalnya pada penelitian yang dilakukan oleh Akhsani Nur Amalia (2015, [3]) dengan model Linear Programming. Penelitian tersebut dilakukan untuk melihat seberapa besar manfaat yang ditimbulkan dengan menggunakan metode optimasi pada perencanaan produksi. Penelitian tersebut membuktikan bahwa manfaat penggunaan metode optimasi tidak signifikan yaitu hanya sebesar $0,05 \%$. Penelitian serupa dilakukan oleh Donatus Feriyanto Simamora (2017, [4]) dengan model Mixed Integer Linear Programming. Penelitian tersebut dilakukan untuk meminimasi total biaya perencanaan produksi di CV. XYZ Cikarang. Hasil dari penelitian tersebut membuktikan bahwa penghematan yang dapat dilakukan dengan metode optimasi hanya sebesar 0,4\%. Umumnya, analisis dilakukan untuk satu kasus tertentu. Tetapi apakah pengaruh yang tidak signifikan akan tetap berlaku pada berbagai kondisi kasus yang berbeda? Hal ini yang menjadi pemicu untuk melakukan penelitian terhadap faktor faktor yang berpengaruh dalam perencanaan produksi. Oleh karena itu, persoalan dari penelitian ini yaitu apakah penggunaan metode optimasi signifikan dalam meminimumkan total biaya perencanaan produksi pada berbagai kondisi faktor?

\subsection{Tujuan Penelitian}

Tujuan dari penelitian ini yaitu untuk mengetahui apakah pengaruh dari penggunaan metode optimasi signifikan dalam meminimumkan biaya perencanaan produksi pada berbagai kondisi faktor.

\section{METODOLOGI}

Agar tujuan penelitian dapat dicapai dengan baik, dilakukan langkah - langkah penelitian seperti pada Gambar 1. 


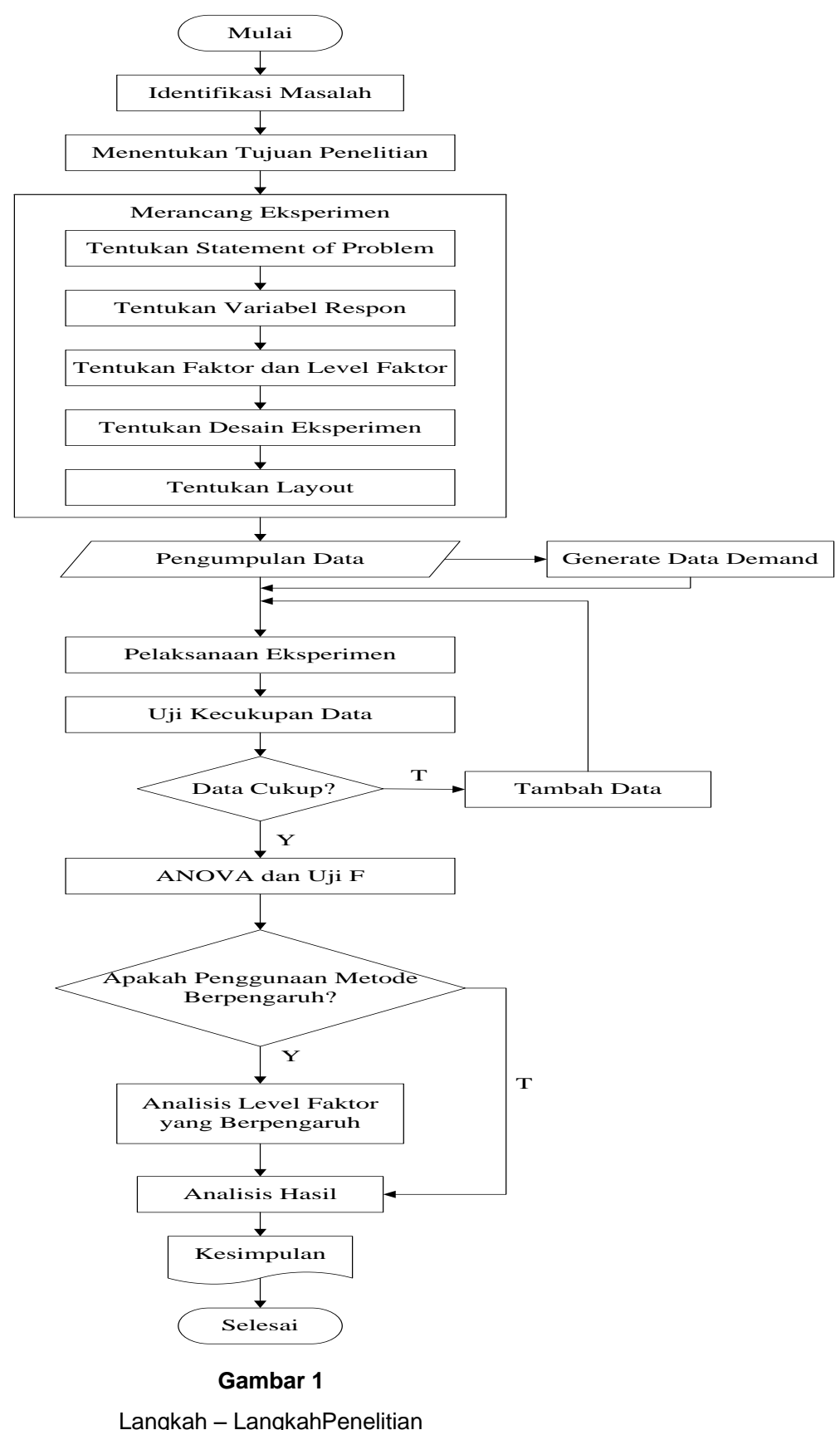

Ada lima langkah utama untuk melakukan

Perancangan eksperimen bertujuan untuk penelitian berbasis eksperimen, yaitu : mengetahui desain eksperimen apa yang Langkah $\mathrm{Ke}$ - 1. Merancang Eksperimen akan digunakan dalam penelitian. Variabel 
respon dalam eksperimen ini yaitu total biaya perencanaan produksi. Selanjutnya, rancangan eksperimen dibuat dengan menentukan faktor dan level faktor.

a. Penentuan Faktor

Faktor yang ingin diteliti dalam penelitian ini adalah faktor metode perencanaan produksi. Metode yang akan diteliti adalah metode optimasi dan metode heuristik. Selain itu, terdapat empat faktor lain yang ikut berpengaruh yaitu stabilitas demand, biaya hiring, biaya lay off dan biaya simpan. Dalam penelitian ini, biaya hiring dan biaya lay off akan dinyatakan sebagai rasio biaya hiring terhadap biaya lay off. Oleh karena itu, terdapat tiga faktor lain yang akan menjadi faktor nuisance yaitu stabilitas demand, rasio biaya hiring terhadap biaya lay off dan biaya simpan.

\section{b. Penentuan Level Faktor}

Level faktor adalah sejumlah nilai faktor yang mungkin dalam perancangan percobaan dimana nilainya tergantung pada asumsi - asumsi tertentu. Dalam penelitian ini masing - masing faktor dicoba dengan tiga level faktor. Level faktor untuk faktor metode yaitu metode optimasi (M1), metode heuristik 1 dengan strategi konstan (M2) dan metode heuristik 2 dengan strategi sesuai demand (M3). Level faktor untuk stabilitas demand yaitu demand dengan range 400 (V1), demand dengan range 100 (V2) dan demand dengan range 1600 (V3). Level faktor untuk rasio biaya hiring dan lay off yaitu rasio 0,4 (R1), rasio 0,1 (R2) dan rasio 0,9 (R3). Level faktor untuk biaya simpan yaitu biaya simpan rendah sebesar Rp. 10 per unit per bulan (OS1), biaya simpan sedang sebesar Rp. 478 per unit per bulan (OS2) dan biaya simpan tinggi sebesar $R p$. 1640 per unit per bulan (OS3).

\section{c. Desain Eksperimen}

Dalam penelitian ini, faktor yang ingin diteliti yaitu faktor metode. Sementara itu, terdapat tiga faktor lain yang ikut berpengaruh yaitu faktor stabilitas demand, faktor rasio biaya hiring dan lay off dan faktor biaya simpan. Ketiga faktor tersebut akan menjadi faktor nuisance. Karena terdapat satu faktor yang ingin diteliti dan tiga faktor nuisance, desain eksperimen yang digunakan adalah Graeco Latin Square Design.

\section{d. Layout Eksperimen}

Layout dari Graeco Latin Square Design dengan tiga level faktor dapat dilihat pada Gambar 2. 


\begin{tabular}{|c|c|c|c|}
\hline Rasio Biaya & \multicolumn{3}{|c|}{ Biaya Simpan } \\
\cline { 2 - 4 } H \& L & OS1 & OS2 & OS3 \\
\hline R1 & M1V1 & M2V2 & M3V3 \\
\hline R2 & M2V3 & M3V1 & M1V2 \\
\hline R3 & M3V2 & M1V3 & M2V1 \\
\hline
\end{tabular}

Gambar 2

Layout Graeco Latin Square Design

\section{Langkah Ke - 2. Pengumpulan Data}

Data yang digunakan dalam penelitian ini yaitu:

1. Data demand

2. Data rasio biaya hiring dan lay off

3. Data biaya simpan

4. Inventory awal

5. Tenaga kerja awal

6. Jam kerja efektif

7. Waktu baku

8. Biaya regular time

9. Biaya over time

10. Biaya tenaga kerja

11. Biaya sub kontrak

12. Hari kerja

\section{Langkah Ke - 3. Pelaksanaan Eksperimen}

Setelah melakukan pengumpulan data, selanjutnya lakukan eksperimen. Eksperimen dilakukan untuk setiap treatment. Untuk mempermudah pelaksanaan eksperimen, treatment berdasarkan layout dibuat ke dalam bentuk tabel perlakuan eksperimen. Tabel perlakuan eksperimen dapat dilihat pada Tabel 1.
Tabel 1

Perlakuan Eksperimen

\begin{tabular}{|c|c|c|c|c|c|c|c|c|c|c|c|c|}
\hline \multicolumn{13}{|c|}{ Perlakuan Eksperimen } \\
\hline \multirow{2}{*}{ Treatment } & \multicolumn{3}{|c|}{ Metode } & \multicolumn{3}{|c|}{ Demand } & \multicolumn{3}{|c|}{ Rasio Biaya H \& L } & \multicolumn{3}{|c|}{ Biaya Simpan } \\
\hline & Mll & II2 & WI3 & $\mathrm{Vl}$ & $\mathrm{V} 2$ & $\mathrm{~V} 3$ & $\mathrm{Rl}$ & R2 & R3 & 0Sl & 0 S2 & $0 \$ 3$ \\
\hline 1 & $\mathrm{~V}$ & & & V & & & $\mathrm{V}$ & & & $\mathrm{V}$ & & \\
\hline 2 & & $\mathrm{~V}$ & & & $\mathrm{~V}$ & & $\mathrm{~V}$ & & & & $\mathrm{~V}$ & \\
\hline 3 & & & $\mathrm{~V}$ & & & $\mathrm{~V}$ & $\mathrm{~V}$ & & & & & V \\
\hline 4 & & $\mathrm{~V}$ & & & & V & & $\mathrm{V}$ & & $\mathrm{V}$ & & \\
\hline 5 & & & $\mathrm{~V}$ & V & & & & $\mathrm{V}$ & & & $\mathrm{V}$ & \\
\hline 6 & $\mathrm{~V}$ & & & & $\mathrm{~V}$ & & & $\mathrm{~V}$ & & & & $\mathrm{~V}$ \\
\hline 7 & & & $\mathrm{~V}$ & & $\mathrm{~V}$ & & & & V & $\mathrm{V}$ & & \\
\hline 8 & $\mathrm{~V}$ & & & & & $\mathrm{~V}$ & & & $\mathrm{~V}$ & & $\mathrm{~V}$ & \\
\hline 9 & & $\mathrm{~V}$ & & $\mathrm{~V}$ & & & & & $\mathrm{~V}$ & & & $\mathrm{~V}$ \\
\hline Lיק & riv & 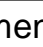 & & dilo & 00 & & & & h & $1 y$ & $k$ & 1 \\
\hline
\end{tabular}

replikasi. Tabel 2 menunjukkan hasil eksperimen 10 replikasi.

Tabel 2

Hasil Eksperimen 10 Replikasi

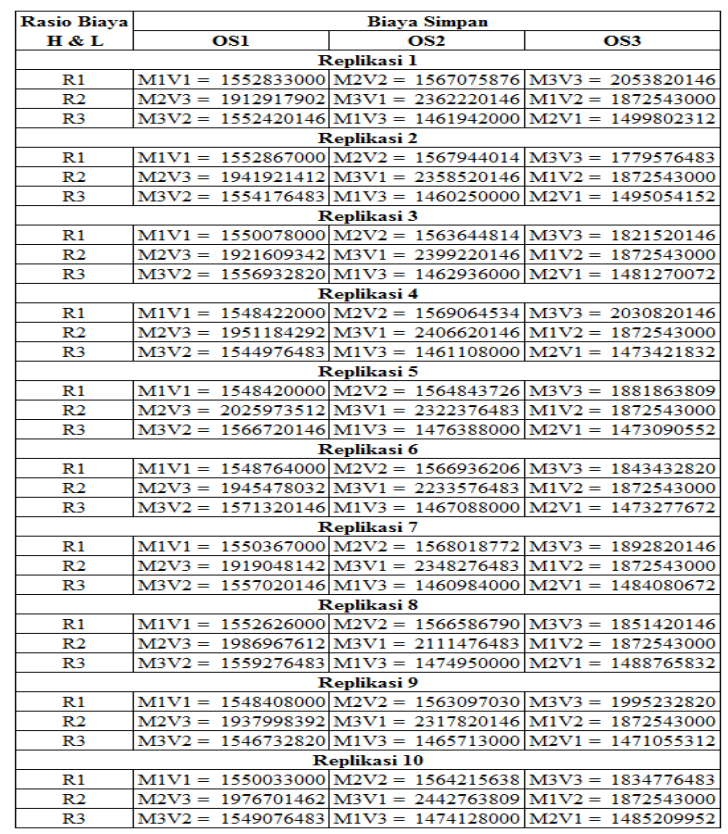

\section{Langkah Ke - 4. Uji Kecukupan Data}

Uji kecukupan data dilakukan untuk mengetahui jumlah minimal replikasi dalam eksperimen. Setelah diperoleh hasil eksperimen 10 replikasi, selanjutnya lakukan uji kecukupan data. Uji kecukupan data 
diperoleh dengan persamaan 1. (Vincent Gaspersz, 1991 [5])

$r=\frac{2 t_{\alpha / 2}^{2} s^{2}}{d^{2}}$

Berdasarkan hasil uji kecukupan data, diperoleh jumlah replikasi yang dibutuhkan sebanyak 10,64. Oleh karena itu, eksperimen akan dilakukan kembali untuk replikasi ke11.

\section{Langkah $\mathrm{Ke}$ - 5. Anova dan Uji F}

ANOVA dan Uji $F$ dilakukan untuk mengetahui apakah faktor metode berpengaruh secara signifikan dalam perencanaan produksi. Dalam ANOVA dihitung nilai sum of squares, degrees of freedom, mean square dan Fhitung. Uji $\mathrm{F}$ dilakukan dengan membandingkan nilai $F$ hitung dengan nilai $F$ tabel.

\section{HASIL}

Berdasarkan uji kecukupan data, jumlah minimal replikasi dalam penelitian ini adalah 10,64. Oleh karena itu, eksperimen kembali dilakukan untuk memperoleh hasil eksperimen replikasi ke - 11. Setelah melaksanakan eksperimen sebanyak 11 replikasi, diperoleh hasil eksperimen 11 replikasi seperti pada Tabel 3.

Setelah diperoleh hasil eksperimen sebanyak 11 replikasi kemudian lakukan perhitungan ANOVA. Perhitungan ANOVA dilakukan dengan menghitung nilai sum of square, degree of freedom, mean square dan $\mathrm{F}$ hitung diperoleh tabel ANOVA seperti pada tabel 4.

\section{Tabel 3}

Hasil Eksperimen 11 Replikasi

\begin{tabular}{|c|c|c|c|}
\hline \multirow{2}{*}{\begin{tabular}{|c|} 
Rasio Biaya \\
H\& L
\end{tabular}} & \multicolumn{2}{|r|}{ Biaya Simpan } & \multirow{2}{*}{ Total (Yi) } \\
\hline & 0S1 & $0 \mathrm{~S}_{2}$ & \\
\hline \multicolumn{4}{|c|}{ Replikasi l } \\
\hline R1 & M1V1 $=1552833000$ & $\mathrm{M} 2 \mathrm{~V} 2=1567075876 \mid \mathrm{M} 3 \mathrm{~V} 3=2053820146$ & 5173729022 \\
\hline $\mathrm{R} 2$ & M2V3 $=1912917902$ & 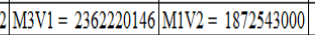 & 6147681048 \\
\hline R3 & $\mathrm{M} 3 \mathrm{~V} 2=1552420146$ & 6 M1V3 $=1461942000 \quad$ M2V1 = 1499802312 & 4514164458 \\
\hline \multicolumn{4}{|c|}{ Replikasi2 } \\
\hline R1 & $\mathrm{M} 1 \mathrm{V1}=1552867000$ & \begin{tabular}{|l|l|l|} 
M2V2 $=1567944014$ & M3V3 $=1779576483$ \\
\end{tabular} & 4900387497 \\
\hline R2 & M2V3 $=1941921412$ & \begin{tabular}{|l|l|l|} 
M3 & V1 $=2358520146$ & M1V2 $=1872543000$ \\
\end{tabular} & 6172984558 \\
\hline R3 & M3V2 $=1554176483$ & 3 M1V3 $=1460250000 \quad$ M2V1 $=1495054152$ & 4509480635 \\
\hline \multicolumn{4}{|c|}{ Replikasi 3} \\
\hline $\mathrm{R} 1$ & M1V1 $=1550078000$ & $\mathrm{M} 2 \mathrm{~V} 2=1563644814 \mid \mathrm{M} 3 \mathrm{~V} 3=1821520146$ & 4935242960 \\
\hline R2 & M2V3 $=1921609342$ & M3V1 $=2399220146 \mid \mathrm{M} 1 \mathrm{~V} 2=1872543000$ & 6193372488 \\
\hline R3 & $\mathrm{M} 3 \mathrm{~V} 2=1556932820$ & M1V3 $=1462936000$ M2V1 $=1481270072$ & 4501138892 \\
\hline \multicolumn{4}{|c|}{ Replikasi 4} \\
\hline $\mathrm{R} 1$ & M1V1 $=1548422000$ & $\mathrm{M} 2 \mathrm{~V} 2=1569064534 \mid \mathrm{M} 3 \mathrm{~V} 3=2030820146$ & 5148306680 \\
\hline $\mathrm{R} 2$ & M2V3 $=1951184292$ & $\mathrm{M} 3 \mathrm{V1}=2406620146 \mathrm{M} 1 \mathrm{~V} 2=1872543000$ & 6230347438 \\
\hline R3 & M3V2 $=1544976483$ & M1V3 $=1461108000 \mid$ M2V1 $=1473421832$ & 4479506315 \\
\hline \multicolumn{4}{|c|}{ Replikasi 5} \\
\hline R1 & MiV1 $=1548420000$ & M22 $2=1564843726 \mid$ M3V3 $=1881863809$ & 4995127535 \\
\hline $\mathrm{R} 2$ & M2V3 $=2025973512$ & $2 \mathrm{M} 3 \mathrm{~V} 1=2322376483 \mathrm{M} 1 \mathrm{~V} 2=1872543000$ & 6220892995 \\
\hline R3 & $\mathrm{M} 3 \mathrm{~V} 2=1566720146$ & 6 M1V3 $=1476388000 \mid$ M2V1 $=1473090552$ & 4516198698 \\
\hline \multicolumn{4}{|c|}{ Replikasi 6} \\
\hline $\mathrm{R} 1$ & M1V1 $=1548764000$ & M2V2 $=1566936206 \mid \mathrm{M} 3 \mathrm{~V} 3=1843432820$ & 4959133026 \\
\hline $\mathrm{R} 2$ & M2V3 $=1945478032$ & $\mathrm{M} 3 \mathrm{V1}=2233576483 \mathrm{M} 1 \mathrm{~V} 2=1872543000$ & 6051597515 \\
\hline R3 & $\mathrm{M} 3 \mathrm{~V} 2=1571320146$ & M1V3 $=1467088000 \mid$ M2V1 $=1473277672$ & 4511685818 \\
\hline \multicolumn{4}{|c|}{ Replikasi 7} \\
\hline R1 & $\mathrm{M} 1 \mathrm{V1}=1550367000$ & M2V2 $=1568018772 \mid \mathrm{M} 3 \mathrm{~V} 3=1892820146$ & 5011205918 \\
\hline $\mathrm{R} 2$ & M2V3 $=1919048142$ & M3V1 $=2348276483$ M1V2 $=1872543000$ & 6139867625 \\
\hline R3 & $\mathrm{M} 3 \mathrm{~V} 2=1557020146$ & M1V3 $=1460984000$ M2V1 $=1484080672$ & 4502084818 \\
\hline \multicolumn{4}{|c|}{ Replikasi 8 } \\
\hline $\mathrm{R} 1$ & MlV1 $=1552626000$ & $\mathrm{M} 2 \mathrm{~V} 2=1566586790 \mathrm{M} 3 \mathrm{~V} 3=1851420146$ & 4970632936 \\
\hline R2 & M2V3 $=1986967612$ & M3V1 $=2111476483$ MIV2 $=1872543000$ & 5970987095 \\
\hline R3 & M3V2 $=1559276483$ & M1V3 $=1474950000$ M2V1 = 1488765832 & 4522992315 \\
\hline \multicolumn{4}{|c|}{ Replikasi 9} \\
\hline $\mathrm{R} 1$ & M1V1 $=1548408000$ & M2V2 $=1563097030 \quad \mathrm{M} 3 \mathrm{~V} 3=1995232820$ & 5106737850 \\
\hline $\mathrm{R} 2$ & M2V3 $=1937998392$ & $\mathrm{M} 3 \mathrm{~V} 1=2317820146$ M1V2 $=1872543000$ & 6128361538 \\
\hline R3 & $\mathrm{M} 3 \mathrm{~V} 2=1546732820$ & M1V3 $=1465713000$ M2V1 $=1471055312$ & 4483501132 \\
\hline \multicolumn{4}{|c|}{ Replikasi 10} \\
\hline $\mathrm{R} 1$ & M1V1 $=1550033000$ & M2V2 $=1564215638$ M3V3 $=1834776483$ & 4949025121 \\
\hline $\mathrm{R} 2$ & $\mathrm{M} 2 \mathrm{~V} 3=1976701462 \mathrm{I}$ & $\mathrm{M} 3 \mathrm{V1}=2442763809 \mathrm{M} 1 \mathrm{~V} 2=1872543000$ & 6292008271 \\
\hline $\mathrm{R} 3$ & $\mathrm{M} 3 \mathrm{~V} 2=1549076483$. & M1V3 $=1474128000 \mid \mathrm{M} 2 \mathrm{V1}=1485209952$ & 4508414435 \\
\hline \multicolumn{4}{|c|}{ Replikasill } \\
\hline $\mathrm{R} 1$ & M1V1 $=1551188000$ & $\mathrm{M} 2 \mathrm{~V} 2=1560054336-\mathrm{M} 3 \mathrm{~V} 3=2168820146$ & 5288062482 \\
\hline R2 & M2V3 $=2017124872$ & $\mathrm{M} 3 \mathrm{V1}=2229876483 \mathrm{M} 1 \mathrm{~V} 2=1872543000$ & 6119544355 \\
\hline $\mathrm{R} 3$ & $\mathrm{M} 3 \mathrm{~V} 2=1547820146$ & M1V3 $=1466851000 \quad$ M2V1 $=1485379112$ & 4500050258 \\
\hline Total(YI) & 55697403274 & \begin{tabular}{|l|l|}
58894566690 & 58062483763 \\
\end{tabular} & 172654453727 \\
\hline
\end{tabular}


Tabel 4

ANOVA

\begin{tabular}{|c|c|c|c|c|c|}
\hline & Sum of Squares & Degrees of Fredom & Yean Square & Filtung & Ftabel $(5 \%)$ \\
\hline Metode & 1796245041537020000 & 2 & 8981225200768512000 & 306.85 & 3.11 \\
\hline Demand & 311519211628528000 & 2 & 1557596058814264000 & & \\
\hline Rasio Biaya \& \& L & 51770157616330530000 & 2 & 25885078808152560000 & & \\
\hline Biaya Simpan & 166745672984494000 & 2 & $833728364+92247000$ & & \\
\hline Replikasi & 21994731522293800 & 10 & 2199473152229380 & & \\
\hline Error & 2341526600010370000 & 80 & 2926908375012970 & & \\
\hline Iotal & 77076730893039900000 & 98 & & & \\
\hline
\end{tabular}

Berdasarkan tabel ANOVA, nilai $F$ hitung lebih besar dari nilai $\mathrm{F}$ tabel, sehingga $\mathrm{H}_{0}$ ditolak. Artinya penggunaan metode berpengaruh secara signifikan terhadap perencanaan produksi.

\section{KESIMPULAN}

Setelah penelitian berbasis eksperimen dilakukan dan kemudian dianalisis, diperoleh kesimpulan sebagai berikut.

1. Penggunaan metode ternyata berpengaruh secara signifikan terhadap perencanaan produksi. Artinya, penggunaan metode optimasi berpengaruh secara signifikan dalam meminimumkan biaya perencanaan produksi pada berbagai kondisi faktor.

2. Hasil uji level faktor dengan Student Newman Keuls menunjukkan bahwa nilai range lebih besar dari nilai LSR. Artinya perbandingan mean antar level faktor signifikan berbeda. Hal ini membuktikan bahwa perencanaan produksi dengan metode optimasi signifikan dalam meminimumkan biaya perencanaan produksi. Besarnya manfaat penggunaan metode optimasi dalam perencanaan produksi pada berbagai kondisi faktor sebesar $0,65 \%$ sampai $17,8 \%$.

3. Berdasarkan hasil eksperimen, dapat dilihat bahwa metode optimasi paling sesuai digunakan pada saat variasi demand tinggi, rasio biaya hiring dan lay off tinggi dan biaya simpan sedang. Metode heuristik dengan strategi konstan paling sesuai digunakan pada saat variasi demand sedang, rasio biaya hiring dan lay off tinggi serta biaya simpan tinggi. Sementara itu, kondisi paling sesuai untuk menggunakan metode heuristik dengan strategi sesuai demand yaitu pada saat variasi demand rendah, rasio biaya hiring dan lay off tinggi serta biaya simpan rendah.

\section{DAFTAR PUSTAKA}

[1] Sipper, D., Bulfin, R.L. Jr. 1997. Production Planning, Control, and Integration. United States of America : The McGraw-Hill Companies, Inc.

[2] Dimyati, T. T., Dimyati, A. 2010. Operations Research. Bandung : Sinar Baru Algesindo.

[3] Amalia, A. N. 2015. Optimasi Perencanaan Produksi Studi Kasus di Home Industri Hackers. Skripsi tidak diterbitkan. Program Sarjana UNPAS, Bandung. 
Infomatek Volume 20 Nomor 1 Juni 2018: 1 - 8

[4] Simamora, D. F. 2017. Optimasi Perencanaan Produksi Perakitan Wiring Herness Dengan Menggunakan Model Mixed Integer Linear Programming Pada CV. XYZ Cikarang. Diakses tanggal 13 Juli 2017.

[5] Gaspersz, V.. $1991 . \quad$ Metode Perancangan Percobaan. Bandung : CV. ARMICO, hal 25-26. 